\title{
Estudos em Raciocínio Combinatório: investigações e práticas de ensino na Educação Básica*
}

\section{Studies in Combinatorial Reasoning: investigations and practices K-12}

\author{
Rute Elizabete de Souza Rosa Borba ${ }^{* *}$ \\ Cristiane de Arimatéa Rocha ${ }^{* *}$ \\ Juliana Azevedo*****
}

\begin{abstract}
Resumo
O presente artigo trata de pesquisas desenvolvidas, ao longo dos últimos cinco anos, pelo Grupo de Estudos em Raciocínio Combinatório do Centro de Educação da Universidade Federal de Pernambuco - Geração. As linhas de investigação do grupo são apresentadas, bem como seus principais referenciais teóricos. Nas investigações realizadas pelo grupo, recursos didáticos são analisados e são apresentados e discutidos resultados de pesquisas desenvolvidas junto a estudantes de distintos níveis e modalidades de ensino, bem como são debatidos estudos realizados com professores da Educação Básica. $\mathrm{O}$ conjunto de resultados obtidos possibilita reflexões referentes a como o raciocínio combinatório se desenvolve, quais as dificuldades a serem superadas e como práticas podem ser mais eficientes no ensino de Combinatória.
\end{abstract}

Palavras-chave:Raciocínio combinatório. Estudantes e Professores. Educação Básica.

\begin{abstract}
This paper presents research carried out over the past five years, by the Grupo de Estudos em Raciocínio Combinatório do Centro de Educação da Universidade Federal de Pernambuco - Geração. The group's research lines are presented in the paper, as well as the main theoretical references used. Investigation by the group on teaching resources are analysed, research results developed with students of different levels and types of education are presented and discussed, as well as studies with K-12 teachers. The set of results obtained enable reflections concerning how combinatorial reasoning develops, what are the difficulties to be overcome and how practices can be more effective in teaching Combinatorics.
\end{abstract}

Keywords: Combinatorial reasoning. Students and Teachers. K-12.

\footnotetext{
* Os estudos relatados foram parcialmente financiados pela FACEPE (APQ-1095-7.08/08), pelo CNPq (476665/2009-4) e por bolsas de mestrado pela Capes.

PhD pela Oxford Brookes University, UK; Professora Associada da Universidade Federal de Pernambuco (UFPE), Recife, Pernambuco, Brasil. Endereço para correspondência: Rua Acadêmico Hélio Ramos, S/N, Várzea, 50.670-901, Recife, Pernambuco, Brasil. E-mail: resrborba@gmail.com

*** Doutoranda do Programa de Pós-Graduação em Educação Matemática e Tecnológica pela Universidade Federal de Pernambuco (UFPE). Professora da Universidade Federal de Pernambuco (UFPE), Caruaru, Pernambuco, Brasil. Endereço para correspondência: Rua Acadêmico Hélio Ramos, S/N, Várzea, 50.670-901. Email: tiane_rocha@yahoo.com.br

***** Doutoranda do Programa de Pós-Graduação em Educação Matemática e Tecnológica pela Universidade Federal de Pernambuco (UFPE), Recife, Pernambuco, Brasil. Endereço para correspondência: Rua Acadêmico Hélio Ramos, S/N, Várzea, 50.670-901. E-mail: azevedo.juliana1987@gmail.com
} 


\section{Apresentando o Grupo de Estudos em Raciocínio Combinatório - Geração}

Em 2009, foi registrado no Diretório de Grupos de Pesquisa do Conselho Nacional de Desenvolvimento Científico e Tecnológico (CNPq), o Grupo de Estudos em Raciocínio Combinatório do Centro de Educação da Universidade Federal de Pernambuco - Geração. Desde então - já passados mais de cinco anos - o Geração tem desenvolvido e divulgado pesquisas referentes à Combinatória e à Probabilidade, sendo este último um conceito em estreita conexão com o primeiro. Segundo Bryant e Nunes (2012), referindo-se a Inhelder e Piaget (1976), o raciocínio combinatório é essencial ao raciocínio probabilístico, uma vez que a Combinatória é necessária para o levantamento sistemático do espaço amostral, a partir do qual se pode determinar probabilidades.

O raciocínio combinatório pode ser definido como um modo de pensar presente na análise de situações nas quais, dados determinados conjuntos, deve-se agrupar seus elementos, de modo a atender critérios específicos (de escolha e/ou ordenação dos elementos) e determinar-se - direta ou indiretamente - o número total de agrupamentos possíveis (BORBA, 2010). A importância do desenvolvimento desse tipo de raciocínio se deve ao fato de possibilitar um modo de pensar necessário em situações cotidianas (tais como organização de equipes, de campeonatos esportivos, de cardápios etc.) e, também, aplicado a diversas áreas do conhecimento (tais como Biologia, Química, Estatística, Ciências da Computação dentre outras - em situações classificatórias, por exemplo).

Tendo em vista o desenvolvimento do raciocínio combinatório na Educação Básica, o Geração tem realizado investigações junto a crianças, adolescentes, jovens e adultos de diferentes níveis e modalidades de ensino, bem como tem realizado pesquisas com professores do Ensino Fundamental e Médio. Os estudos têm sido desenvolvidos no âmbito do Programa Institucional de Bolsas de Iniciação Científica (PIBIC) - tanto com estudantes de graduação, quanto alunos de Ensino Médio - e em programas de pós-graduação - em Educação e em Educação Matemática e Tecnológica. Os resultados dos estudos têm sido divulgados em eventos científicos nacionais e internacionais e em artigos de divulgação científica, bem como têm sido produzidos materiais de formação de professores e desenvolvidos atividades e materiais manipulativos que podem ser utilizados junto a alunos desde a Educação Infantil até o Ensino Médio.

Cinco são as linhas de pesquisa do Geração, com seus respectivos objetivos centrais: 
- Análise e produção de recursos - Levantar abordagens de ensino de problemas de Combinatória em propostas curriculares, em livros-texto e em meios digitais; produzir atividades, em meio impresso e/ou digital, para a Educação Básica.

- Avaliação de conhecimentos - Analisar como tem se dado a avaliação dos problemas multiplicativos - em particular os da Combinatória - em instrumentos de larga escala e em outros processos avaliativos ocorridos dentro da escola; propor processos avaliativos de desenvolvimento do raciocínio combinatório.

- Desenvolvimento cognitivo - Observar o desenvolvimento da compreensão de problemas combinatórios de alunos da Educação Infantil, do Ensino Fundamental (anos iniciais e finais), da Educação de Jovens e Adultos e do Ensino Médio.

- Formação de professores - Identificar concepções de professores sobre as naturezas de problemas combinatórios, sobre dificuldades de alunos e sobre formas de intervenção para superação de dificuldades; observar salas de aula quando do ensino de problemas de Combinatória.

- Intervenções pedagógicas - Realizar estudos para o desenvolvimento do raciocínio combinatório de crianças, adolescentes, jovens e adultos.

O presente texto objetiva apresentar e discutir pesquisas desenvolvidas pelo Geração, nos últimos cinco anos, refletindo sobre o que se aprendeu referente a como se desenvolve o raciocínio combinatório e sobre quais práticas de ensino podem auxiliar esse desenvolvimento por parte de estudantes da Educação Básica ${ }^{1}$.

\section{Pressupostos teóricos do ensino e da aprendizagem da Combinatória}

A Combinatória estuda técnicas de contagem - direta e implícita - de agrupamentos possíveis, a partir de elementos dados, que satisfaçam a determinadas condições. A contagem nos problemas combinatórios vai além de uma mera enumeração de objetos expostos, pois são contadas maneiras possíveis de combinar dados elementos, de modo que todas as combinações, que atendem certos critérios, sejam consideradas.

Morgado et al.(2006) afirmam que na Análise Combinatória ${ }^{2}$ são estudadas estruturas e relações discretas, sendo os problemas mais frequentes - e os mais usualmente trabalhados na Educação Básica - a contagem de subconjuntos de um conjunto finito que atendam a certas condições dadas.

\footnotetext{
${ }^{1}$ Mais informações sobre o Geração podem ser obtidas em http://geracaoufpe.blogspot.com.br/

${ }^{2}$ No presente artigo, Combinatória e Análise Combinatória são tomadas como sinônimas.
} 
Batanero, Godino e Navarro-Pelayo (1996) colocam que há cinco tipos distintos de problemas combinatórios: a) existência - observação da possibilidade, ou não, de solução diante dos elementos dados e condições determinadas; b) enumeração - listagem de todos os subconjuntos de elementos que satisfazem as condições postas; c) contagem - determinação do número total de soluções, sem necessariamente listar todas; d) classificação sistematização dos casos segundo critérios apropriados; e) otimização - busca da melhor condição para a obtenção de determinadas soluções para um problema.

Na Educação Básica são tratados, em geral, problemas de enumeração e de contagem. Além da limitação em termos de problemas combinatórios tratados, restringem-se, também, os tipos de situações a determinados níveis de ensino, apesar de recomendações em contrário de documentos oficiais como os Parâmetros Curriculares Nacionais (BRASIL, 1997).

Vergnaud (1991), Nunes e Bryant (1997) e os Parâmetros Curriculares Nacionais (BRASIL, 1997) chamam a atenção que, dentre os problemas multiplicativos, um caso particular - geralmente trabalhado no Ensino Fundamental - envolve pensamento combinatório, denominado pelos autores e documento acima citado de, respectivamente, produto de medidas, produto cartesiano e situações associadas à ideia de combinatória. Esse tipo de problema envolve dois ou mais conjuntos disjuntos que são combinados, a partir da seleção de um elemento de cada um dos conjuntos independentes, gerando um novo conjunto de elementos, de natureza distinta da dos conjuntos disjuntos dados.

Ao se estudar a Combinatória no Ensino Médio, outros problemas são tratados, com casos nos quais elementos podem, ou não, ser repetidos. Nesse nível de ensino, geralmente os problemas abordados são: arranjos (a partir de um conjunto maior são escolhidos elementos cuja ordenação gera possibilidades distintas), combinações (que se assemelham aos arranjos em termos de escolha de elementos, com a diferença de que a ordem dos elementos não gera possibilidades distintas) e permutações (todos os elementos do conjunto são utilizados, apenas a ordem de apresentação dos mesmos varia).

Observa-se, dessa forma, a natureza variada, e por vezes complexa, dos problemas de Combinatória - situações problematizadoras nas quais não há, sempre, indicação clara de caminhos diretos de solução, mas necessita-se examiná-las com atenção para verificar o tipo de problema combinatório e/ou qual(is) estratégia(s) sistemática(s) pode(m) ser utilizada(s) para encontrar solução viável para o mesmo. A observação de casos possíveis também auxilia na análise de probabilidades, pois para o julgamento do que seja provável, improvável e impossível, o levantamento de possibilidades se faz necessário. 
Segundo Inhelder e Piaget (1976), o raciocínio combinatório constitui-se em um dos componentes do estágio avançado de pensamento denominado de operacional formal, o qual possui como propriedade geral a distinção entre o real e o possível. A Combinatória viabiliza o levantamento de todas as possíveis relações de uma situação e a análise - pela combinação de procedimentos de experimentação e de análise lógica - da validade das possibilidades. Assim, o raciocínio combinatório possui um caráter fundamentalmente hipotético-dedutivo, sendo, portanto, base de raciocínio científico, no qual é possível isolar variáveis, manter algumas constantes e variar outras.

Sendo esse modo de pensar alcançado mais plenamente em estágios avançados de desenvolvimento cognitivo, não se deve desconsiderar que a gênese do raciocínio combinatório pode iniciar-se antes do período de pensamento operacional formal e pode desenvolver-se por meio de interações entre maturação cognitiva e experiências sociais tanto as ocorridas fora da escola quanto as vivenciadas em contextos escolares.

Fischbein (1975) ressalta que a instrução escolar desempenha um grande papel no desenvolvimento do raciocínio combinatório. Esta conclusão foi tirada a partir de estudos empíricos nos quais a instrução - em particular com o uso de árvores de possibilidades permitiu avanços no desenvolvimento desse modo de pensar, auxiliando estudantes em sua falta de capacidade de enumeração sistemática.

Outro aspecto a se considerar é o de que as situações combinatórias possuem particularidades e relações que as diferenciam entre si, mas estas se unem por aspectos em comum, constituintes, portanto de um mesmo campo conceitual - o das estruturas multiplicativas (VERGNAUD, 1991).

Pessoa e Borba (2009), a partir da concepção de articulação de conceitos apresentada por Vergnaud (1986), defendem que os distintos tipos de problemas combinatórios se desenvolvem desde os anos iniciais de escolarização e - amparadas por resultados de investigação empírica a ser descrita a seguir - argumentam que se deve trabalhar em todos os níveis e modalidades de ensino com problemas de produto cartesiano, arranjo, combinação e permutação. A justificativa é a de que há relações básicas de Combinatória contidas nesses quatro tipos de problemas, e levar os estudantes a terem contato com esta variedade de situações pode possibilitar um mais amplo desenvolvimento do raciocínio combinatório.

Vergnaud $(1986,1991)$ tem sido um referencial teórico base nos estudos do Geração, ao ressaltar como se dá o desenvolvimento de conceitos por parte de estudantes, e os referenciais teóricos base referentes aos conhecimentos docentes têm sido Shulman (2005) e Ball, Thames e Phelps (2008). 
Quanto aos conhecimentos necessários ao professor, Shulman (2005) propõe as seguintes categorias: a) conhecimento do conteúdo a ser trabalhado em sala de aula; b) conhecimento didático geral, referente a princípios e estratégias gerais de manejo e organização da classe, não necessariamente associados a conteúdos específicos; c) conhecimento do currículo, em especial os programas das classes ensinadas pelo docente; d) conhecimento didático do conteúdo, conhecimento do ensino de conteúdos específicos; e) conhecimento dos estudantes e de suas características; f) conhecimentos dos contextos educativos, que inclui o funcionamento da classe, a gestão de espaços escolares e características de comunidades e culturas; g) conhecimento dos objetivos, das finalidades e dos valores educativos, de seus fundamentos filosóficos e históricos.

Ball, Thames e Phelps (2008), a partir da observação de práticas docentes, aplicaram pressupostos de Shulman (2005) a conhecimentos de professores que ensinam Matemática. Descreveram conhecimentos de conteúdo e conhecimentos pedagógicos de conteúdo. Se pensarmos em termos de Combinatória, os conhecimentos mobilizados pelos professores ao ensinarem tal conteúdo são: a) o conhecimento geral de Combinatória - não exclusivo de professores, mas que se refere ao saber resolver problemas combinatórios; b) o conhecimento especializado sobre a Combinatória, possuído por docentes, como conhecer os diferentes tipos de problemas combinatórios: produtos cartesianos, arranjos, combinações e permutações; c) o conhecimento horizontal da Combinatória, qual seja a compreensão de como problemas combinatórios se relacionam entre si por nível de complexidade; d) o conhecimento que relaciona a Combinatória aos aprendizes da mesma, tal como, conhecer como estudantes desenvolvem o raciocínio combinatório; e) o conhecimento de Combinatória relacionado ao ensino, ou seja, conhecer estratégias de ensino de Combinatória e f) o conhecimento do currículo referente à Combinatória, i.e., como Combinatória é estruturada ao longo do currículo.

Seguem-se temáticas investigadas pelo Geração e os principais resultados obtidos.

\section{Recursos didáticos que podem auxiliar o desenvolvimento do raciocínio combinatório}

Os recursos didáticos representam um aliado do professor na busca pela motivação e interesse dos alunos, inclusive na experimentação e sistematização de conteúdos matemáticos. Como indicado por Shulman (2005), as orientações curriculares, livros didáticos e outros materiais podem, e muito, influenciar práticas docentes. Nesse sentido, se faz necessário pesquisar esses recursos para refletir sobre as possibilidades e desafios, além 
de sistematizar a utilização e a escolha desses materiais para promover a compreensão e elaboração de conceitos matemáticos. Ressalta-se que recursos estão intimamente relacionados a situações que dão significado aos conceitos, relações e propriedades implícitas e explícitas às situações e representações simbólicas utilizadas - aspectos muito importantes na conceitualização, segundo Vergnaud (1986). Dentre os variados recursos, as investigações realizadas pelo Geração focalizaram, especificamente, o livro didático, softwares e objetos de aprendizagem.

Barreto e Borba (2010) observaram como foram tratados problemas combinatórios em livros do aluno e manuais do professor de cinco coleções dos anos iniciais de escolarização. Verificou-se que os tipos com maiores percentuais totais de apresentação foram a combinação e o produto cartesiano e que, por vezes, os problemas combinatórios eram inseridos em capítulos que tratam do sistema de numeração decimal e de estruturas aditivas. Identificou-se uma ampla variedade de representações simbólicas utilizadas, mas nenhum trabalho com o professor quanto às propriedades invariantes da Combinatória, nem sobre os diferentes significados envolvidos.

Martins e Borba (2010) investigaram como as 19 obras aprovadas no Plano Nacional do Livro de Alfabetização 2008 - voltados para a alfabetização de jovens e adultos abordaram problemas multiplicativos. Observou-se que, em geral, os livros analisados dedicaram maior parte para a leitura e escrita de textos, com menor espaço para a alfabetização matemática. Os problemas de maior frequência foram os de multiplicação e divisão e um número muito reduzido de problemas de Combinatória, mas os mesmos foram inseridos por meio de contextos adequados ao público-alvo.

Santana e Borba (2010) objetivaram investigar como os livros didáticos de $5^{\circ}$ ano do Ensino Fundamental abordam a Probabilidade. Selecionaram, aleatoriamente, onze coleções das aprovadas no PNLD 2007, sobre as quais analisaram a maneira de introdução desse conceito, além de verificarem os tipos de atividades e representações simbólicas utilizadas. As autoras evidenciaram as poucas atividades que abordam a Probabilidade nos livros analisados, e indicaram que, nesses livros, o conceito de probabilidade geralmente se apresenta de dois modos: (1) relacionado a ideias de porcentagem, fração ou de combinatória; (2) a partir de experimentos, jogos, ou problemas relacionados à noção de chance. Ao analisarem os tipos de representações presentes nas atividades, as autoras destacaram a pouca variedade e as subdividiram em quatro categorias: apenas enunciado, desenho e fotografias, tabelas e gráficos. Enfatizaram, ainda, a ausência de orientações no Manual do Professor, não 
apresentando indicação de sugestões sobre como se pode trabalhar para o desenvolvimento do raciocínio probabilístico.

As pesquisas sobre a análise de livros didáticos evidenciam que há uma variedade de situações combinatórias presentes em coleções de livros de Matemática dos anos iniciais - do Ensino Regular e da Educação de Jovens e Adultos - mas em quantidade muito reduzida, quando comparado ao total de problemas de multiplicação e divisão. Ressalta-se, também, que não é chamada a atenção do professor sobre a diversificação de problemas e sobre as particularidades de cada tipo de problema de Combinatória, tampouco sobre o desenvolvimento da prática de ensino de Probabilidade. Dessa forma, o trabalho matemático a ser desenvolvido, a partir do uso desses livros didáticos, pode ficar limitado a poucas oportunidades que permitam o desenvolvimento de raciocínios combinatórios e probabilísticos, principalmente se considerarmos que o livro didático pode servir como recurso para estudo do professor.

Leite, Pessoa, Ferraz e Borba (2009) analisaram cinco softwares/objetos de aprendizagem voltados para o ensino da Combinatória: Diagramas de Árbol (AGUIRRE, 2005), ML Combiner (LEES, 2001), Combinação (RIVED, 2008), Permutação (RIVED, 2008a) e Arranjo (RIVED, 2008b). Tomando como base a Teoria dos Campos Conceituais proposta por Vergnaud (1986), foram identificados os significados abordados, as formas de representação simbólica apresentadas e sugeridas pelos softwares e objetos de aprendizagem, bem como os invariantes explicita e implicitamente trabalhados.

Observou-se que os softwares educativos e os objetos de aprendizagem analisados, com exceção do Diagramas de Árbol, trabalham com tipos limitados de situações combinatórias - em termos de significados abordados e respectivas propriedades e relações invariantes a eles associados - e permitem pouca exploração por parte dos usuários, pois tendem a sugerir que, após algumas poucas tentativas, se utilize a fórmula apropriada para a situação dada.

Além da limitação desses recursos, referente à formalização rápida das situações combinatórias, Leite et al. (2009) salientam que, para haver possibilidade de melhor uso de recursos tecnológicos para o ensino da Combinatória, variadas representações simbólicas devem ser viabilizadas. Outras questões importantes a serem consideradas são: feedback compatível com o tipo de invariante a ser mobilizado e ajudas ao usuário que oportunizem a reflexão sobre a situação a ser resolvida e possibilitem a reformulação de estratégias de resolução. 
Ferraz, Borba e Azevedo (2010) analisaram como o software Diagramas de Árbol pode servir de suporte ao desenvolvimento do raciocínio combinatório, a partir do acompanhamento de 19 estudantes de $7^{\circ}$ ano de escolarização, agrupados em duplas e trios, ao resolverem oito problemas combinatórios. Cada problema possuía dois itens que envolviam números que levavam a menor e a maior número de possibilidades na solução, sendo o primeiro item solucionado com o auxílio do software e o segundo item por meio de estratégia de resolução escolhida pelos estudantes. As autoras observaram que a árvore de possibilidades - seja virtualmente produzida, seja no lápis e papel - pode ser um recurso que auxilie os estudantes na compreensão dos variados tipos de problemas combinatórios. Porém, apesar de expectativa anteriormente levantada, verificou-se que o uso do software para os primeiros itens, nem sempre foi suficiente para auxiliar os estudantes na generalização necessária para o segundo item - no qual a representação de todas as possibilidades era inviável.

Pela análise de recursos tecnológicos, observa-se o potencial destes na prática de ensino, mas verificam-se limitações dos softwares e objetos de aprendizagem que precisam ser levadas em consideração para viabilizar o melhor aproveitamento dos mesmos no ensino da Combinatória.

O que esse conjunto de estudos pode nos apontar sobre o uso de recursos didáticos para o ensino de Combinatória e Probabilidade? Quanto aos livros didáticos, recomendamos que os professores dos anos iniciais fiquem atentos a seções - além das voltadas para o ensino da multiplicação - nas quais situações combinatórias podem ser trabalhadas, pois, como apontado por Barreto e Borba (2010), há problemas combinatórios presentes em seções do sistema de numeração decimal e também das estruturas aditivas. A partir do apresentado por esses autores, bem como por Santana e Borba (2010), ressaltamos que o professor necessitará buscar orientações em outras fontes, uma vez que nos manuais de professores dos livros de anos iniciais não se discute, claramente, situações combinatórias ou probabilísticas. Referente aos livros destinados à EJA, observamos a necessidade de o professor promover mais trabalho com Combinatória. Os poucos contextos trabalhados, como observado por Martins e Borba (2010), apontam que há diversas situações de interesse de jovens e adultos que podem ser utilizadas para o desenvolvimento de seus raciocínios combinatórios. Quanto ao uso de recursos tecnológicos para o ensino de Combinatória, ressaltamos a necessidade de o professor atentar sobre como ele mesmo poderá prover feedback e ajudas ao usuário, uma vez que retornos e auxílios não estão presentes nesses recursos virtuais - como observado por Leite et al. (2009). O único software identificado que possibilita trabalhar com diferentes tipos 
de situações combinatórias foi o apontado por Ferraz, Borba e Azevedo (2010) - o Diagramas de Árbol. Observamos que esse software, ao construir árvores de possibilidades, permite, como recomendado por Fischbein (1975), que se pense em situações combinatórias de modo sistematizado e mais generalizado.

\section{0 que alunos de diferentes níveis e modalidades de ensino sabem e o que podem aprender sobre Combinatória}

Borba, Pessoa, Barreto e Lima (2011) relataram estudo com 718 estudantes (do $2^{\circ}$ ao $9^{\circ}$ ano do Ensino Fundamental regular; $1^{\circ}$ ao $3^{\circ}$ ano do Ensino Médio regular; e dos anos iniciais de escolarização da Educação de Jovens e Adultos até o Ensino Médio dessa modalidade, além de cursos de Ensino Médio profissionalizantes), resolvendo oito problemas de produto cartesiano, combinação, arranjo e permutação. As autoras destacaram que a média de acertos aumentou com o passar dos anos de escolaridade, em ambas as modalidades de ensino. Entretanto, essa média, que poderia chegar até 8 pontos, variou de 0,22 a 3,45 pontos, o que aponta para um baixo índice de acertos, estando a modalidade da Educação de Jovens e Adultos com as médias mais baixas em comparação com os níveis correspondentes da educação regular. Dentre os problemas, o que teve o maior índice de acerto foram os de produto cartesiano e os mais difíceis foram os de permutação. Além disso, as autoras enfatizaram que as representações utilizadas para resolução dos problemas são as mesmas antes e depois dos alunos terem estudado formalmente sobre o conteúdo, tais como: desenhos, listagens, operações aritméticas simples, principalmente adição e subtração. As fórmulas foram utilizadas por poucos alunos do Ensino Médio regular, e em geral, não correspondiam à situação apresentada, ocasionando erro na resolução do problema. Concluiu-se que o desenvolvimento do raciocínio combinatório se inicia desde os primeiros anos de escolarização e ainda não se conclui com o fim do Ensino Médio e, para proporcionar um desenvolvimento mais amplo do raciocínio combinatório, é necessária a utilização de diferentes situações, com seus invariantes correspondentes, e o uso de diversificadas representações simbólicas.

Pessoa e Borba (2012) realizaram entrevistas clínicas com crianças da Educação Infantil, com idades entre 5 e 6 anos, por meio de uso de figuras. As crianças eram questionadas sobre quatro situações, uma de cada tipo de problema combinatório. As autoras observaram que as crianças bem novas já entendem alguns invariantes da Combinatória, principalmente os relacionados com a escolha de elementos. O invariante de ordenação teve 
um maior grau de dificuldade, e, ainda mais difícil foi esgotar todas possibilidades solicitadas no problema. Concluíram, assim, que situações combinatórias simples podem ser trabalhadas de modo concreto desde a Educação Infantil.

A partir desses estudos de sondagem, foram realizados estudos de intervenção, com estudantes matriculados na modalidade regular de ensino, bem como, com estudantes da Educação de Jovens e Adultos (EJA), tanto com a utilização de um software educativo, bem como com diferentes representações simbólicas por meio do lápis e papel.

Barreto e Borba (2012) investigaram a influência de diferentes tipos de representações simbólicas (listagem e/ou árvore de possibilidades) na resolução de problemas combinatórios por alunos da EJA. Os grupos que passaram por intervenção, seja com um ou os dois tipos de representação simbólica, avançaram em seus desempenhos. As autoras destacam a importância de um trabalho sistematizado com variadas representações simbólicas para o ensino-aprendizagem da Combinatória.

Azevedo e Borba (2013) analisaram a influência do uso da árvore de possibilidades com e sem o uso do software Diagramas de Árbol. Participaram do estudo 40 alunos do $5^{\circ}$ ano de duas escolas da rede Municipal de Recife, divididos em 4 grupos, com 10 alunos cada, sendo dois grupos experimentais, que aprendiam com ou sem o uso do software; e dois grupos controle - o primeiro aprendeu problemas multiplicativos não relacionados com a Combinatória, por meio de desenhos, e o segundo não participou de nenhuma sessão de intervenção. Antes das intervenções realizadas com os grupos, os alunos resolveram um préteste. Após as intervenções, foram realizados dois pós-testes, um imediato e outro, nove semanas após o primeiro.

As autoras destacam que ambos os grupos experimentais avançaram, de modo significativo, em seus conhecimentos combinatórios, quando comparados os seus desempenhos no pré e pós-testes. O grupo que participou de intervenções por meio de lápis e papel obteve um desempenho um pouco melhor que o grupo que aprendeu por meio do software Diagramas de Árbol, o que pode ser explicado em termos da necessidade de transferir o aprendido no software para o lápis e papel. Entretanto, a diferença entre esses dois grupos não foi significativa, levando as autoras a concluírem que o ensino da Combinatória, por meio de árvores de possibilidades, seja com o uso do software ou com o lápis e papel, pode ser uma boa prática de ensino com alunos dos anos iniciais do Ensino Fundamental.

Azevedo e Borba (2013) também observaram que, entre os problemas combinatórios, as situações de permutação foram as que os alunos apresentaram maior dificuldade. Isso porque no software, bem como no lápis e papel, a quantidade de ramos da árvore pode ser 
muito grande, levando à conclusão de que a dificuldade nesse tipo de questão pode estar relacionada à quantidade de escolhas que devem ser realizadas nos problemas de permutação (3 ou 4 etapas de escolha), em comparação com as etapas de escolha para os demais problemas combinatórios (2 etapas de escolha).

Vega e Borba (2014) analisaram a influência das etapas de escolha na resolução dos diversos tipos de problemas combinatórios. Participaram do estudo 128 alunos do $6^{\circ}$ ano do Ensino Fundamental que responderam um teste de sondagem. Nos testes eram comparados problemas com 2, 3 e 4 etapas de escolha. Entre os resultados encontrados, as autoras destacam que, diferentemente de estudos anteriores nos quais se tem os problemas de produto cartesiano mais fáceis em relação aos de permutação, quando controlada as etapas de escolha, os problemas de produto cartesiano passaram a ser os mais difíceis (quando ambos trabalham com 4 etapas de escolha).

Além dos estudos envolvendo problemas combinatórios simples, também foram investigados os conhecimentos de alunos, nos diferentes níveis de ensino, sobre problemas combinatórios condicionais. Braz e Borba (2012) investigaram alunos do $5^{\circ}, 7^{\circ}$ e $9^{\circ}$ ano do Ensino Fundamental respondendo problemas de arranjo condicional em 22 categorias diferentes que abordavam condições relativas a escolha, posição, proximidade e ordem. As autoras observaram que no $5^{\circ}$ ano os alunos já possuem alguma compreensão acerca das condições apresentadas nos problemas, mas os alunos de $9^{\circ}$ ano apresentam melhores resultados.

Borba, Araújo e Braz (2013) investigaram o conhecimento em problemas de arranjo condicional de alunos do $1^{\circ}$ e $3^{\circ}$ anos do Ensino Médio. Como resultados, destaca-se que os alunos do $3^{\circ}$ ano do Ensino Médio, que já passaram por instruções formais sobre a Combinatória, apresentaram melhores resultados em relação aos alunos do $1^{\circ}$ ano. Entretanto, esses alunos, que não haviam passado por instruções formais sobre o conteúdo, conseguiram resolver alguns problemas por meio de procedimentos menos formais. As dificuldades elencadas pelas autoras estão relacionadas, num primeiro momento, com a quantidade de condições consideradas no problema, e, também, com as condições de ter "no mínimo e ter no máximo determinados elementos não explicitados, com determinada característica, fixo.

Quanto à probabilidade, especificamente sobre as consequências da aleatoriedade e quanto à formação e categorização do espaço amostral, há estudo em andamento que pretende investigar e analisar a compreensão de crianças, de $1^{\circ}, 3$ e $5^{\circ}$ anos do Ensino Fundamental, por meio de método clínico piagetiano em situações de jogos, como apontado por Silva e Borba (2014). Os resultados desse estudo serão indicativos para prática de ensino em salas de 
aula de anos iniciais do Ensino Fundamental, tanto de conceitos probabilísticos, quanto de problemas combinatórios, uma vez que tratam de levantamento de espaço amostral.

Uma análise do conjunto de pesquisas sobre o aprendizado de Combinatória e de Probabilidade por parte de estudantes, nos leva a considerar que esses conteúdos levam um longo período para seu aprendizado (como indicado por Borba, Pessoa, Barreto e Lima (2011), mas há indícios de noções intuitivas por parte de crianças bem novas, como atestam Pessoa e Borba (2012) e Silva e Borba (2014).Os estudos de sondagem apontam, ainda, que além dos tipos de situações combinatórias, há outros fatores que podem influenciar o desempenho dos estudantes - como o número de etapas, apontado por Vega e Borba (2014), e isso deve ser aspecto a ser considerado no ensino, bem como o estímulo ao trabalho mais avançado com problemas condicionais, como os investigados por Borba e Braz (2012) e Borba, Araújo e Braz (2013). A partir de noções intuitivas já possuídas - referentes ao levantamento de espaços amostrais, considerando escolha e ordenação de elementos, estudos, como os de Barreto e Borba (2012) e de Azevedo e Borba (2013), evidenciaram que intervenções - mesmo com curtos espaços de tempo - auxiliam para um eficiente desenvolvimento de raciocínio combinatório, ao estimularem o uso de variadas formas de representação de problemas combinatórios.

\section{0 que professores pensam e fazem referente ao ensino de Combinatória}

Investigações sobre os conhecimentos dos professores promovem reflexões sobre práticas de ensino e de aprendizagem, e nas pesquisas desenvolvidas no Geração foram investigados, especificamente, os conhecimentos necessários para o ensino de Combinatória e de Probabilidade nos diferentes níveis de escolarização. As investigações se fundamentam nos estudos de Shulman (2005), que proporciona uma discussão sobre que base de conhecimentos se faz necessária para o professor ensinar, e Ball, Thames e Phelps (2008) que questionam e trazem essas discussões para o professor de Matemática.

Rocha (2011), com o objetivo de analisar os conhecimentos que professores possuem de Combinatória e seu ensino, entrevistou seis professores que ensinam Matemática (dois que atuavam nos anos iniciais do Ensino Fundamental, dois nos anos finais e dois no Ensino Médio). A entrevista focalizou: o conhecimento dos professores com relação ao conteúdo de Combinatória, diferenciando os tipos de problemas e a nomenclatura utilizada; o conhecimento pedagógico de Combinatória, analisando a dificuldade de problemas 
combinatórios, as estratégias de resolução desses problemas e buscando alternativas para a superação de dificuldades apresentadas na resolução desses problemas por alunos.

Sobre o aspecto do conhecimento de Combinatória dos professores, Rocha (2011) verificou que os professores dos anos iniciais investigados não utilizaram a nomenclatura usual na diferenciação dos problemas combinatórios e classificaram os problemas com relação à forma e ao enunciado do problema. Os professores dos anos finais, assim como os professores do Ensino Médio, diferenciaram alguns dos problemas combinatórios e destacaram aspectos como a ordenação e repetição, refletindo conhecimento especializado de Combinatória, adaptado a partir da discussão dos domínios de conhecimento de Ball, Thames e Phelps (2008). Mesmo os professores com formação específica tiveram dificuldades na diferenciação dos problemas de arranjo e combinação.

Sobre o conhecimento pedagógico de Combinatória, ao investigar sobre o tipo de problema combinatório que causa mais dificuldade nos alunos, os professores dos anos iniciais identificaram os problemas de produto cartesiano, enquanto que os professores de Matemática (anos finais e Ensino Médio) escolheram os problemas de combinação. Sobre as estratégias privilegiadas na resolução de problemas combinatórios, os professores dos anos iniciais consideraram a listagem, a tabela e a árvore de possibilidades com relação ao problema de produto cartesiano, o que excetuando a listagem, também foi considerado pelos professores dos anos finais do Ensino Fundamental, os quais preferiram a utilização do princípio multiplicativo.

Uma das dificuldades analisadas por Rocha (2011) em problemas combinatórios foi o esgotamento de possibilidades quando na resolução por meio da listagem. Ao propor as estratégias de ensino para superação dessa dificuldade, os professores dos anos iniciais sugeriram o uso de materiais concretos, além de uma proposta de resolução de problemas com a socialização de estratégias e um trabalho no qual utilizariam mais problemas de mesma natureza para discussão na sala. Os professores dos anos finais preferiram um trabalho de comparação com outras estratégias, como, por exemplo, a árvore de possibilidades. Essa perspectiva, também foi escolhida pelos professores do Ensino Médio, sugerindo o trabalho em duplas para comparação das mesmas, no entanto, esses professores sentiram a necessidade de uma maior sistematização da resolução.

Observamos que os professores dos anos iniciais apresentaram dificuldades com relação ao conteúdo de Combinatória, no entanto, sugeriram diferentes recursos para o desenvolvimento desse trabalho. Já os professores de formação matemática, buscaram 
aspectos mais formais nesse tipo de problema, mas indicaram recursos menos variados para o ensino deste conteúdo.

Santana e Borba (2012, p.1) buscaram analisar como professores do Ensino Fundamental concebem o ensino da probabilidade, conceito em estreita relação com a Combinatória. Para isso, entrevistaram quatro professores de anos iniciais do Ensino Fundamental. A pesquisa revelou que os participantes demonstraram dificuldades na compreensão do conceito de probabilidade e que "nomenclaturas como fenômeno aleatório, espaço amostral, acaso e evento, necessárias na formalização do conceito de probabilidade, não foram evidenciadas pelos professores entrevistados". Esse resultado chama a atenção sobre possíveis dificuldades que podem ser resultantes do não entendimento do que seja espaço amostral em problemas combinatórios.

Assis (2014) objetivou analisar o efeito de uma formação continuada sobre Combinatória, tendo como base as situações, invariantes e representações simbólicas (VERGNAUD, 1986) de cada tipo de problema. Para isso foi realizado uma formação com professoras que atuam nos anos iniciais, sobre a qual a autora buscou identificar mudanças apresentadas nas reflexões e práticas de uma professora que participou desse processo. As atividades realizadas nos encontros de formação permitiram que as professoras (1) diferenciassem os tipos de problemas combinatórios, identificando alguns de seus invariantes (escolha e ordenação); (2) elaborassem problemas combinatórios, permitindo a reflexão sobre os contextos e as grandezas numéricas envolvidas nos problemas; (3) resolvessem, por meio de diferentes estratégias, os problemas combinatórios, enfatizando diferentes representações simbólicas; (4) elaborassem e executassem uma proposta de aula sobre Combinatória, refletindo sobre os recursos e procedimentos utilizados; (5) refletissem coletivamente sobre a aula realizada, analisando diferenças entre o planejado e o executado; (6) a partir das reflexões do último encontro, elaborassem e executassem uma nova proposta de aula.

Os resultados dessa pesquisa apresentaram que a formação continuada promoveu mudanças com relação ao conhecimento de Combinatória da professora, especificamente na diferenciação dos tipos de problemas combinatórios e no invariante de escolha, já que a mesma apresentou maiores reflexões sobre esses problemas e suas características na entrevista final. Entretanto, o invariante ordenação, segundo Assis (2014), não foi totalmente compreendido, pois a professora continuou a apresentar dificuldades na diferenciação de problemas de arranjo e combinação. Mudanças também ocorreram no tratamento das representações simbólicas, quando a professora utilizou diferentes representações durante as 
aulas ministradas, reconhecendo o desenho, a listagem e a árvore de possibilidades como auxiliares na compreensão da Combinatória.

Lima (2015), no segundo estudo da sua dissertação, investigou os conhecimentos de professores envolvidos na utilização do Princípio Fundamental da Contagem (PFC) na resolução de problemas combinatórios e na construção das fórmulas. Nesse sentido, realizou entrevistas com três professores de Matemática com atuação nos anos finais do Ensino Fundamental e/ou Médio. A entrevista baseou-se na tipologia de domínios de conhecimento de Ball e colaboradores, especificamente adaptada, para analisar os conhecimentos mobilizados sobre o PFC enquanto estratégia de resolução.

A partir de análise com auxílio do software web Qualitative Data Analysis (webQDA), a autora observou, com maior frequência, o conhecimento especializado do conteúdo com relação ao PFC. Segundo Lima (2015, p.94) o professor faz uso desse tipo de conhecimento "quando trata explicitamente do PFC como uma estratégia que foi válida na resolução do problema apresentado", quando diferencia os tipos de problemas e/ou identifica seus invariantes.

Em relação ao conhecimento do PFC e ensino, Lima (2015) indicou que esse foi o segundo domínio mais frequente ao longo das entrevistas. A autora apontou que os participantes elegeram a árvore de possibilidades como uma estratégia alternativa para os problemas combinatórios, todavia não houve, por parte dos professores, a especificação de como essa estratégia pode ser interligada ao PFC. A ordem de grandeza dos problemas combinatórios, foi outro aspecto sinalizado pelos professores entrevistados (quanto menor for o número de possibilidades, aumenta o número de estratégias possíveis).Os resultados apontam, ainda, que há pouco indício de relações entre o PFC e as fórmulas, o que segundo Lima (2015), seria uma boa maneira de subsidiar o professor nas aulas, além de contribuir para desenvolvimento do raciocínio combinatório de seus alunos.

Observamos, a partir dessas pesquisas com professores, que se fazem necessárias propostas de formação continuada, focalizando os diferentes domínios de conhecimentos, inserindo reflexões, tanto com relação ao conhecimento especializado, como também, conhecimento relativo ao ensino de Combinatória e, também, de Probabilidade, como indicam Santana e Borba (2012).Verificamos, como apontado por Rocha (2011), que os conhecimentos docentes de Combinatória têm forte influência de formações iniciais, mas também são fortemente afetados por experiências de ensino. Já, a partir de resultados, como os obtidos Lima (2015), indicamos a necessidade de professores compreenderem melhor como diferentes estratégias de resolução de problemas combinatórios - tais como listagens, 
árvores de possibilidades, o PFC e as fórmulas - podem se articular em situações de ensino e aprendizagem em sala de aula.

\section{Considerações finais}

O conjunto de investigações realizadas pelo Grupo de Estudos em Raciocínio Combinatório - Geração - buscou levantar conhecimentos sobre a prática de ensino e sobre a aprendizagem de Combinatória e Probabilidade na Educação Básica. Salienta-se que os estudos foram desenvolvidos em busca de um acúmulo de conhecimentos, pois o que ficou como questão em aberto em um estudo anterior, objetivou-se responder em estudos posteriores. Essa característica de grupos de pesquisa é muito importante, pois objetiva construir conhecimentos que se complementam, nesse caso, em particular, quanto ao desenvolvimento do raciocínio combinatório e probabilístico por parte de estudantes da Educação Infantil ao Ensino Médio.

Os estudos aqui descritos e analisados possuem resultados que se articulam entre si, pois o que é proposto no ensino de Combinatória e Probabilidade - por meio de livros didáticos e recursos tecnológicos - têm influência sobre o conhecimento docente, tanto referente ao conteúdo em si, quanto ao que diz respeito ao aluno, ao ensino e ao currículo. Por sua vez, o conhecimento docente, certamente, influencia o desenvolvimento do raciocínio combinatório e probabilístico dos estudantes da Educação Básica.

O levantamento de recursos didáticos para o ensino de Combinatória evidenciou, em livros didáticos, propostas de atividades que contemplam diferentes significados presentes em variadas situações combinatórias e suas respectivas relações e propriedades (invariantes), bem como diversidade de formas de representar simbolicamente essas situações. Em relação a outros problemas multiplicativos, a Combinatória e a Probabilidade são pouco trabalhadas. As atividades propostas, em sua maioria, são apropriadas ao público ao qual se destina - sejam crianças do Ensino Fundamental, sejam jovens e adultos da EJA. Entretanto, não há indicação aos professores sobre os diferentes tipos de situações combinatórias, e as especificidades de cada tipo, nem se discutem as diferentes formas de representação dessas situações e de como podem auxiliar os estudantes no desenvolvimento de seus raciocínios combinatórios.

A investigação dos recursos tecnológicos - tais como softwares e objetos de aprendizagem - mostrou limites e possibilidades em seus usos. Observou-se que, em particular nos anos iniciais do Ensino Fundamental, os softwares e objetos de aprendizagem voltados à Combinatória são limitados, e mesmo para os anos finais do Ensino Fundamental, 
ou para o Ensino Médio, muitos não se mostram apropriados, pois limitam-se ao uso de fórmulas, além de não fornecerem adequadas ajudas ao usuário e feedbacks que possibilitem reflexões por parte dos usuários. Recursos tecnológicos apropriados visam trabalhar com diferentes tipos de situações e possibilitam que os usuários utilizem outros meios - menos formais - de busca de respostas para os problemas postos.

Os estudos de sondagem, junto a alunos de diferentes níveis e modalidades de ensino (Educação Infantil, Ensino Fundamental, Ensino Médio e EJA), evidenciaram quais conhecimentos os alunos já possuem de situações combinatórias (não condicionais e condicionais) e situações probabilísticas, bem como quais dificuldades são necessárias superar. Maiores facilidades com algumas situações combinatórias podem ser influenciadas pela escolaridade, pela familiaridade com a situação, com as relações e propriedades envolvidas (sejam as específicas a cada tipo de situação - arranjos, combinações, permutações ou produtos cartesianos - sejam as relações de escolha, ordem, posição e proximidade), as representações simbólicas utilizadas e pelo número de etapas de escolha envolvidas nos problemas. As intervenções com alunos mostraram formas eficientes de auxiliá-los na superação de suas dificuldades. Um exemplo de dificuldade superada é o de esgotamento de possibilidades, o qual pode, com recursos de ensino tais como a construção virtual ou em lápis e papel de árvores de possibilidades, evidenciar modos sistemáticos de enumeração (de levantamento de espaço amostral).

De forma semelhante, estudos de sondagem de conhecimentos e concepções docentes mostraram o que os professores sabem referente ao ensino e à aprendizagem de Combinatória e do conceito correlato de Probabilidade. Os conhecimentos docentes podem ser influenciados pelas formações (iniciais e continuadas) dos professores, e atenção especial pode ser dada, de modo a auxiliar os professores nos desenvolvimentos de seus conhecimentos de conteúdo e conhecimentos pedagógicos de conteúdo. Apropriação desses conhecimentos podem influenciar o desenvolvimento do raciocínio combinatório por parte de estudantes de todos os níveis e modalidades de ensino.

\section{Referências}

AGUIRRE, C. Diagrama de Árbol. Multimidea. [s.l.]: [s.n.], 2005.

ASSIS, A. Conhecimentos de combinatória e seu ensino em um processo de formação continuada: reflexões e prática de uma professora. 2014. 169 f. Dissertação (Mestrado). Programa de Pós-Graduação em Educação Matemática e Tecnológica, Universidade Federal de Pernambuco, Recife, 2014. 
AZEVEDO, J.; BORBA, R. Combinatória: A construção de árvores de possibilidades por alunos dos anos iniciais com e sem uso de software. Alexandria - Revista de Educação em Ciência e Tecnologia, Florianópolis, v.6, n.2, p. 113-140, jun. 2013.

BALL, D.; THAMES, M.; PHELPS, G. Content Knowledge for Teaching: what makes it special? In: Journal of teacher education, Washington, v.59, n.5, p. 389-407, 2008. Disponível em: $<$ http://jte.sagepub.com/content/59/5/389>. Acesso em: 13 jan. 2013.

BARRETO, F.; BORBA, R. O desenvolvimento do raciocínio combinatório em alunos de um programa de correção de fluxo na modalidade da educação de jovens e adultos. Anais... 6 Encontro Paraibano de Educação Matemática. Monteiro - PB, 9 a 11 de novembro de 2010.

. Estudantes de anos iniciais da Educação de Jovens e Adultos resolvendo problemas combinatórios com listagens e com árvores de possibilidades. Educação Matemática em Revista, v.35, p. 1-12, 2012.

BATANERO, C.; GODINO, J.; NAVARRO-PELAYO, V. Razonamiento combinatorio. Madri: Ed. Sintesis, 1996.

BORBA, R O raciocínio combinatório na educação básica. In: Anais... 10 Encontro Nacional de Educação Matemática. Salvador-BA, 2010.

BORBA, R.; PESSOA, C.; BARRETO, F; LIMA, R.C.G. Children's, young people's and adults' Combinatorial reasoning. Ubuz, B. (ed.). Proceedings of the 35th Conference of the International Group for the Psychology of Mathematics Education, v. 2, p. 169-176. Ankara, Turkey: PME. 2011.

BORBA, R.; ARAÚJO, A; BRAZ, F. A compreensão por alunos do Ensino Médio de problemas combinatórios condicionais. Anais... 11 Encontro Nacional de Educação Matemática. Curitiba - PR, 2013.

BRASIL. Ministério da Educação.Parâmetros Curriculares Nacionais:Matemática. ( $1^{\mathrm{a}}$ a $4^{\mathrm{a}}$ série). Brasília: SEF, 1997.

BRAZ, F.; BORBA, R. A compreensão de problemas combinatórios condicionais por alunos do $5^{\circ}$ ano do Ensino Fundamental. Anais... 20 Congresso de Iniciação Científica da UFPE - CONIC, Recife, 2012.

BRYANT, P.; NUNES, T.Children's understanding of probability: a literature review. NuffieldFoundation. 2012, 86p. Disponível em: $<$ http://www.nuffieldfoundation.org/sites/default/files/files/Nuffield_CuP_FULL_REPO RTv_FINAL.pdf $>$. Acesso em: 22 set. 2014.

FISCHBEIN, E. The Intuitive Sources of Probabilistic Thinking in Children, Reidel. Dordrecht, 1975.

FERRAZ, M.; BORBA, R.; AZEVEDO, J. Usando o software Árbol na construção de árvores de possibilidades para a resolução de problemas combinatórios. Anais.... 10 Encontro Nacional de Educação Matemática. Salvador, 2010.

INHELDER, B.; PIAGET, J. Da lógica da criança à lógica do adolescente. São Paulo: Livraria Pioneira Editora. 1976.

LEES, M. ML Combiner 1.00. [s.l.]: [s.n.], 2001. 
LEITE, M.; PESSOA, C.; FERRAZ, M.; BORBA, R. Softwares Educativos e Objetos de Aprendizagem: Um olhar sobre a Análise Combinatória. Anais... 10 Encontro Gaúcho de Educação Matemática. Jun. 2009, Ijuí - RS.

LIMA, A. Princípio Fundamental da Contagem: conhecimentos de professores de Matemática sobre seu uso na resolução de situações combinatórias. 2015. 138 f. Dissertação (Mestrado). Programa de Pós-Graduação em Educação Matemática e Tecnológica, Universidade Federal de Pernambuco, Recife, 2015.

MARTINS, G.; BORBA, R. Livros didáticos de alfabetização de jovens e adultos: um estudo sobre as estruturas multiplicativas. Anais... 10 Encontro Nacional de Educação Matemática. Salvador, 2010.

MORGADO, A.; PITOMBEIRA, J.; CARVALHO, P.C.; FERNANDEZ, P. Análise Combinatória e Probabilidade. 9. ed. Rio de Janeiro: IMPA/SBM, 2006.

NUNES, T.; BRYANT, P. Crianças fazendo matemática. Porto Alegre: Editora Artes Médicas, 1997.

PESSOA, C; BORBA, R. Quem dança com quem: o desenvolvimento do raciocínio combinatório de crianças de $1^{\text {a }}$ a $4^{\text {a }}$ série. Zetetiké, Campinas. v. 17, jan./jun., 2009.

. Do Young Children Notice what Combinatorial Situations Require? Proceedings... 36th Conference of the International Group for the Psychology of Mathematics Education, v. 1, p. 261. Taipei, Taiwan: PME. 2012.

RIVED. Rede Interativa Virtual de Educação. SEED/MEC. Objeto de Aprendizagem Combinação. Disponível em: $\langle$ http://RIVED.mec.gov.br/atividades/matematica/combinacao/combinacao.swf〉 Acesso em: 15 set. 2008.

.Objeto de Aprendizagem Permutação. Disponível em:

〈http://RIVED.mec.gov.br/atividades/matematica/permutacao/permutacao.swf. $>$. Acesso em: 15 set. $2008 \mathrm{a}$.

. Objeto de Aprendizagem Arranjo. Disponível em:

$\langle$ http://www.RIVED.mec.gov.br/site _objeto_ver.php?codobjeto=218>. Acesso em: 15 set. 2008 b.

ROCHA, C. Formação Docente e o Ensino de problemas combinatórios: diferentes conhecimentos, diversos olhares. 2011. 192 f. Dissertação (Mestrado) - Programa de Pós-Graduação em Educação Matemática e Tecnológica, Universidade Federal de Pernambuco, Recife, 2011.

SANTANA, M.; BORBA, R. Como a probabilidade tem sido abordada nos livros didáticos de Matemática de anos iniciais de escolarização. Anais... 10 Encontro Nacional de Educação Matemática. X ENEM. Salvador - BA, 2010.

. O acaso, o provável, o determinístico: concepções e conhecimentos probabilísticos de professores dos anos iniciais do ensino fundamental. Anais... 3 Simpósio Internacional de Pesquisa em Educação Matemática. III SIPEMAT. Fortaleza - CE. 2012

SHULMAN, L. Conocimiento y enseñanza: fundamentos de la nueva reforma. Profesorado. Revista de currículum y formación del profesorado. Granada. v 9,2, p.1-30, 2005.

SILVA, R.B.; BORBA, R. Situações em Jogos e o Conhecimento Probabilístico de Estudantes dos Anos Iniciais. Anais... 18 Encontro Brasileiro de Estudantes de Pós-Graduação em Educação Matemática. XVIII EBRAPEM. Recife - PE, 2014. 
VEGA, D.; BORBA, R. Etapas de escolha na resolução de produtos cartesianos, arranjos, combinações e permutações. Jornal Internacional de Estudos em Educação Matemática - JIEEM / InternationalJournal for Studies in MathematicsEducation - IJSME, v. 7, n. 3, p. 27-72, 2014.

VERGNAUD, G.El niño, las matemáticas y la realidad - Problemas de la enseñanza de las matemáticas en la escuela primaria. Mexico: Trillas, 1991.

. Psicologia do desenvolvimento cognitivo e didática das matemáticas. Um exemplo: as estruturas aditivas. Análise Psicológica, [s.1.] n. 1, p. 75-90, 1986.

Submetido em Abril de 2015. Aprovado em Agosto de 2015. 